\title{
Magnified Endoscopic View of Primary Follicular Lymphoma at the Duodenal Papilla
}

\author{
Hiroshi Nakase ${ }^{1}$, Minoru Matsuura ${ }^{1}$, Sakae Mikami ${ }^{1}$ and Tsutomu Chiba ${ }^{1}$
}

Key words: follicular lymphoma, duodenal papilla

(DOI: 10.2169/internalmedicine.46.6229)

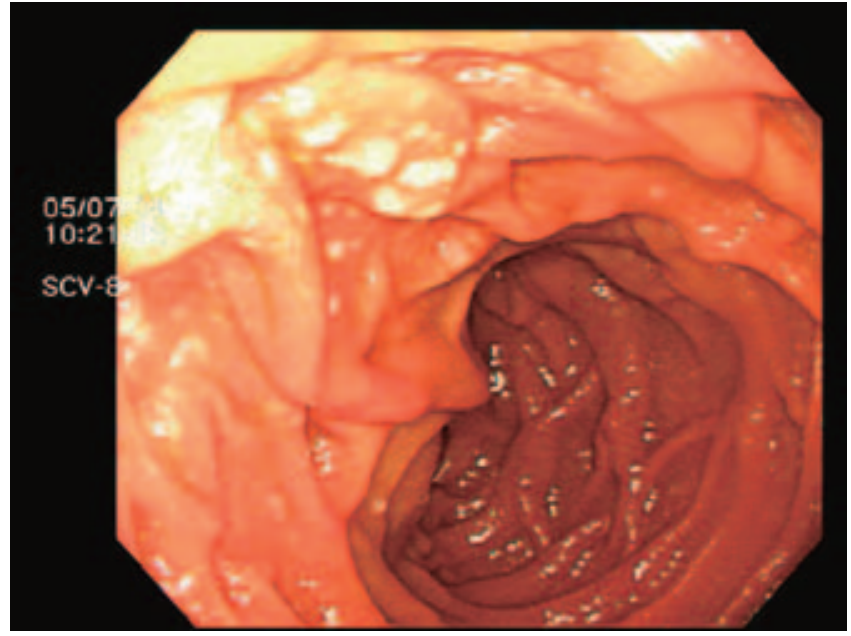

Figure 1. Endoscopic view showing small multiple white granules around the papilla of Vater.

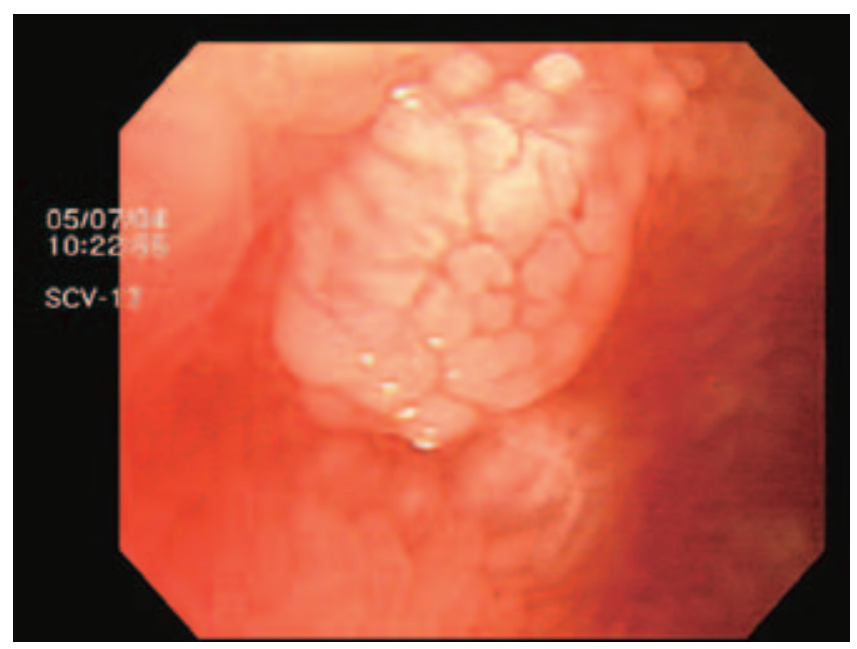

Figure 2. Magnified endoscopic view of the white granule around the duodenal papilla, which was suggestive of a subepithelial or submucosal lesion with local interruption of lymphatic flow.

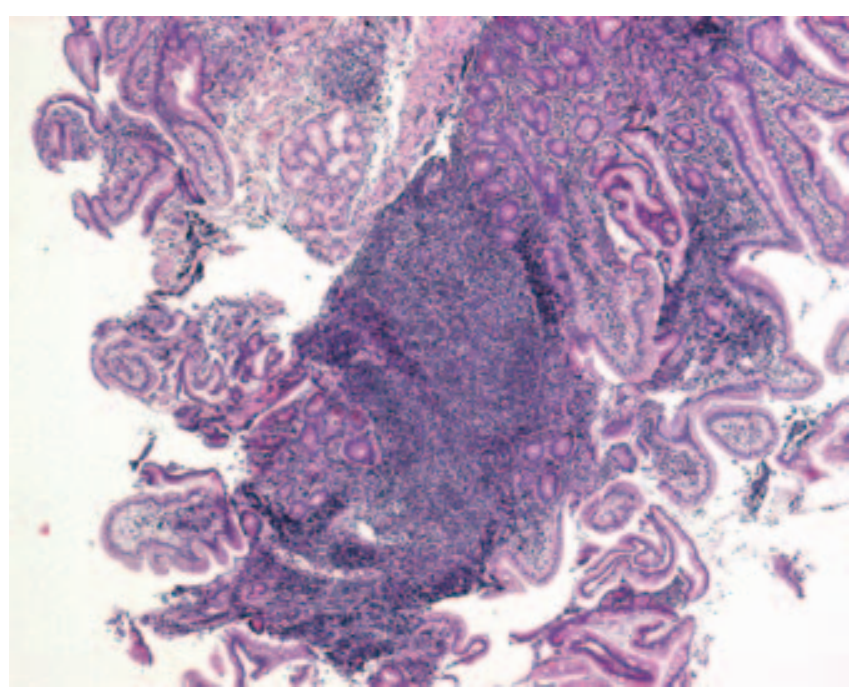

Figure 3. Histological picture of biopsy specimen showing that small cleaved lymphoid cells with some large cells of the centroblastic type were infiltrated into the lamina propria of duodenum.

A 57-year-old asymptomatic woman with no physical findings visited our hospital for further investigation of duodenal lesions. Upper gastrointestinal endoscopy revealed multiple granules with a white color and smooth surface around the major duodenal papilla (Fig. 1). Magnified endoscopic view revealed that the white granules were composed of slightly enlarged and fused villi with a normal pit pattern (Fig. 2). These findings were suggestive of pathogenic change originating from non-epithelial sites with local interruption of lymphatic flow. To make a diagnosis, we took biopsy specimen from these granules. Histopathologic evaluation revealed infiltration of atypical lymphoid cells in the lamina propria of the duodenum (Fig. 3). The atypical cells were positive for CD10 and BCL-2, but negative for CD3 and CD5. Other diagnostic methods showed no abnormal

\footnotetext{
${ }^{1}$ Department of Gastroenterology \& Hepatology, Graduate School of Medicine, Kyoto University, Kyoto Received for publication September 6, 2006; Accepted for publication October 17, 2006

Correspondence to Dr. Hiroshi Nakase, hiropy@kuhp.kyoto-u.ac.jp
} 
DOI: $10.2169 /$ internalmedicine.46.6229

findings. She was diagnosed as having stage I primary folli- cant change of this polypoid lesion was observed after one cular lymphoma of the duodenum. Interestingly, no signifi- year without treatment.

(C) 2007 The Japanese Society of Internal Medicine http://www.naika.or.jp/imindex.html 